\title{
Comparative Efficacy of Amoxicillin-Clavulanate, Cloxacillin, and Vancomycin Against Methicillin-Sensitive and Methicillin-Resistant Staphylococcus aureus Endocarditis in Rats
}

Since the introduction of methicillin into clinical medicine in 1959 the prevalence of Staphylococcus aureus strains resistant to this antibiotic has reached epidemic proportions in certain geographic areas. The therapeutic options for treating such strains are largely limited to vancomycin. The B-lactamase-resistant penicillins and cephalosporins have been controversial for the treatment of infections caused by these organisms [1].

Beta-lactamase inhibitors (e.g., clavulanic acid and sulbactam) have a weak intrinsic antibacterial activity but act synergistically with $\beta$-lactamase-labile antibiotics against most $\beta$-lactamase-producing organisms such as methicillinsensitive $S$. aureus (MSSA). In the case of methicillinresistant $S$. aureus (MRSA), the resistance mechanisms are more complex and less well understood [1]. However, when the $\beta$-lactamases of MRSA strains are inhibited by the addition of clavulanic acid, the minimal inhibitory concentrations (MICs) of amoxicillin and penicillin against these organisms are reduced by 2-4 dilutions to values of 4-16 $\mu \mathrm{g} / \mathrm{mL}$ for most of the strains tested [2-4]. While many authors consider this increase in in vitro activity to be of questionable significance, Washburn and Durack [5] showed with a rabbit model of $S$. aureus endocarditis that the combination of ampicillin and sulbactam was highly effective against endocarditis caused by two different nafcillin-resistant $S$. aureus strains and that the combination was superior to nafcillin alone. Because these in vitro and in vivo observations deserve further scrutiny, we designed this study: $(l)$ to determine the MICs of amoxicillin and oxacillin, alone or in combination with clavulanic acid, for a large number of recent clinical isolates of MSSA and MRSA; and (2) to study the in vivo efficacy of the combination of amoxicillin with clavulanic acid against MSSA and MRSA strains in a rat model of $S$. aureus endocarditis and to compare it to that of cloxacillin and vancomycin.

\section{Materials and Methods}

In vitro study. (1) Microorganisms. A total of 167 strains of $S$. aureus originating in different locales (Eu-

Received for publication 16 August 1988 and in revised form 29 November 1988.

This work was published in part in abstract form in the program of the 27th Interscience Conference on Antimicrobial Agents and Chemotherapy (1987, abstract 930).

This work was supported in part by Beecham Research Laboratories, Bern, Switzerland.

Please address requests for reprints to Dr. M. P. Glauser, Division of Infectious Diseases, Centre Hospitalier Universitaire Vaudois, 1011 Lausanne, Switzerland. rope, the USA, Australia) were studied. All of the strains were $\beta$-lactamase producers and thus were resistant to penicillin. When tested by a disk diffusion method as recommended by the National Committee for Clinical Laboratory Standards (NCCLS) [6], 71 strains were found to be methicillin-sensitive (Kirby Bauer inhibition diameter $\geqslant 13$ $\mathrm{mm}$ using a 1- $\mu \mathrm{g}$ oxacillin disk in Mueller Hinton agar [MH; Difco Laboratories, Detroit] without $\mathrm{NaCl}$ ). Ninetysix strains were methicillin-resistant (Kirby Bauer inhibition diameter $\leqslant 10 \mathrm{~mm}$ under the same testing conditions).

(2) Antibiotics. Standard antimicrobial reference preparations of vancomycin (Eli Lilly, Indianapolis), amoxicillin, oxacillin, amoxicillin-clavulanate (Augmentin), and clavulanic acid (Beecham Research Laboratories, Brockham Park, UK) were used.

(3) Susceptibility testing. MICs were determined by the microbroth dilution method [7] with an automatic device (MIC 2000 Dynatech, FRG). MICs of oxacillin, amoxicillin, and oxacillin in combination with clavulanic acid (added at a fixed concentration of $4 \mu \mathrm{g} / \mathrm{mL}$ ), and amoxicillin-clavulanic acid (in a ratio of 2:1), were performed in cation-supplemented MHB $\left(50 \mathrm{mg} / \mathrm{L}\right.$ of $\mathrm{Ca}^{++}$ and $25 \mathrm{mg} / \mathrm{L}$ of $\mathrm{Mg}^{++}$) with $2 \% \mathrm{NaCl}$. For vancomycin MIC determinations, cation supplementation was not used. Final inocula of $5 \times 10^{5}$ to $5 \times 10^{6} \mathrm{cfu} / \mathrm{mL}$ were prepared from an overnight culture in MH. MICs were determined by visual inspection after $24 \mathrm{~h}$ of incubation at $35^{\circ} \mathrm{C}$. For a selection of strains, $\mathrm{MBC}$ were determined by macrobroth dilution method [8] and defined as the lowest concentration of antibiotic that killed $99.9 \%$ of the initial inoculum after $24 \mathrm{~h}$ of incubation.

In vivo study. (1) Microorganisms. Four different strains of $S$. aureus were studied in the rat model: two MSSA (MSSA-1, MSSA-2) and two MRSA (MRSA-1, MRSA-2).

(2) Production of endocarditis. Sterile vegetations were produced in female Wistar rats $(180-200 \mathrm{~g})$ by modification of a method already described [9]. Briefly, a polyethylene catheter (PP 10, Portex, Hythe, Kent, UK) was inserted across the aortic valve through the right carotid artery and secured with a silk ligature. Rats were injected in the tail vein with $0.5 \mathrm{~mL}$ of saline containing $10^{5} \mathrm{cfu}$ of $S$. aureus (MSSA-1, MSSA-2, MRSA-1, or MRSA-2) either $4 \mathrm{~d}$ (half of the experiments) or $12 \mathrm{~h}$ after catheterization. Both experimental designs produced bacterial counts of $10^{6}-10^{7} \mathrm{cfu} / \mathrm{g}$ of vegetations $12 \mathrm{~h}$ after iv bacterial challenge. Since the effect of treatment was found to be similar after both experimental designs (bacterial challenge $4 \mathrm{~d}$ and $12 \mathrm{~h}$ after catheterization), the results were pooled.

(3) Evaluation of infection. To determine the incidence and the magnitude of valvular infection, control rats cho- 
sen at random were sacrificed $12 \mathrm{~h}$ after iv injection of bacteria (i.e., at the time treatment was started in the test rats). Treated rats were killed after $3 \mathrm{~d}$ of therapy, $12 \mathrm{~h}$ after the last antibiotic injection, when no antibiotic activity was detectable in blood. Aortic vegetations were excised, weighed, homogenized in $1 \mathrm{~mL}$ of saline, and serially diluted and plated. Colonies were counted after $24 \mathrm{~h}$ of incubation at $37^{\circ} \mathrm{C}$, and the results expressed in $\log _{10}$ $\mathrm{cfu} / \mathrm{g}$ of vegetation. This method permitted the detection of $10^{2} \mathrm{cfu} / \mathrm{g}$ of organ. Bacteria recovered from the vegetations of treated rats were routinely stored at $-20^{\circ} \mathrm{C}$ for subsequent MIC determinations.

(4) Treatment regimens. Antibiotics were started $12 \mathrm{~h}$ after infection and were given for $3 \mathrm{~d}$. Treatment was started early to minimize mortality from overwhelming infection. Cloxacillin (Orbenin injectable, $1 \mathrm{~g}$, Beecham Research Laboratories) was given sc at $200 \mathrm{mg} / \mathrm{kg}$ every $5 \mathrm{~h}$. The adult formulation of parenteral Augmentin (Augmentin injectable, $1.2 \mathrm{~g}$, containing amoxicillin and clavulanic acid in a ratio of $5: 1$, Beecham) was given sc at $150 \mathrm{mg} / \mathrm{kg}$ of amoxicillin and $30 \mathrm{mg} / \mathrm{kg}$ of clavulanic acid every $5 \mathrm{~h}$. Two different regimens of vancomycin (Vancocin injectable $500 \mathrm{mg}$, Eli Lilly) were tested: $30 \mathrm{mg} / \mathrm{kg}$ every $12 \mathrm{~h}$ or $30 \mathrm{mg} / \mathrm{kg}$ every $6 \mathrm{~h}$ sc.

(5) Antibiotic serum levels. Serum samples were taken from normal rats at various intervals after one sc injection and levels of cloxacillin and of vancomycin were determined by microbiologic assay using a test strain of Bacillus subtilis (Subtilis spore suspension, Difco Laboratories). The serum values of amoxicillin and clavulanic acid were measured by Beecham Research Laboratories using a microbiologic assay.

(6) Statistical evaluation. Nonparametric analysis with the Wilcoxon Mann-Whitney test was used to compare the bacterial counts in the vegetations.

\section{Results}

In vitro study. (1) MSSA strains. Figure 1 (upper panels) illustrates results. Of the MSSA strains, $62(87 \%)$ of 71 were resistant to amoxicillin according to the criteria of the NCCLS (MIC $\geqslant 0.5 \mu \mathrm{g} / \mathrm{mL}$ ) [7]: $\mathrm{MIC}_{50} 8 \mu \mathrm{g} / \mathrm{mL}$; $\mathrm{MIC}_{90} 128 \mu \mathrm{g} / \mathrm{mL}$; range $\leqslant 0.12-256 \mu \mathrm{g} / \mathrm{mL}$. The addition of clavulanic acid reduced the $\mathrm{MIC}_{50}$ for amoxicillin to $1 \mu \mathrm{g} / \mathrm{mL}$, the $\mathrm{MIC}_{90}$ to $2 \mu \mathrm{g} / \mathrm{mL}$, and the range to $\leqslant 0.12-4 \mu \mathrm{g} / \mathrm{mL}$, making the strains susceptible to Augmentin (MIC $\leqslant 4 / 2 \mu \mathrm{g} / \mathrm{mL}$ ). All strains were susceptible to oxacillin $\left(\mathrm{MIC}_{50} 0.25 \mu \mathrm{g} / \mathrm{mL}, \mathrm{MIC}_{90} 0.5 \mu \mathrm{g} / \mathrm{mL}\right.$, range $\leqslant 0.125-1.0 \mu \mathrm{g} / \mathrm{mL}$ ), and their MICs were only slightly influenced by the addition of clavulanic acid $\left(\mathrm{MIC}_{50} \leqslant .012\right.$ $\mu \mathrm{g} / \mathrm{mL} ; \mathrm{MIC}_{90} 0.25 \mu \mathrm{g} / \mathrm{mL} ;$ range $\leqslant 0.12-0.5 \mu \mathrm{g} / \mathrm{mL}$ ). All MSSA strains were also susceptible to vancomycin $\left(\right.$ MIC $_{\mathbf{s o}}$ $1 \mu \mathrm{g} / \mathrm{mL} ; \mathrm{MIC}_{90} 1 \mu \mathrm{g} / \mathrm{mL}$; range $1-2 \mu \mathrm{g} / \mathrm{mL}$ ).

(2) MRSA strains. The lower panels of figure 1 illus- trate the results. The addition of clavulanic acid reduced the amoxicillin $\mathrm{MIC}_{50}$ from 32 to $8 \mu \mathrm{g} / \mathrm{mL}$, the $\mathrm{MIC}_{90}$ from 128 to $16 \mu \mathrm{g} / \mathrm{mL}$, and the range from $8-128$ to $2-32 \mu \mathrm{g} / \mathrm{mL}$, but most of these organisms remained resistant to Augmentin according to the criteria of the NCCLS (MIC $\geqslant$ $8 / 4 \mu \mathrm{g} / \mathrm{mL}$ ). In contrast, the addition of clavulanic acid to oxacillin did not influence the MIC (oxacillin $\mathrm{MIC}_{50}$ in the presence of clavulanic acid $32 \mu \mathrm{g} / \mathrm{mL}, \mathrm{MIC}_{90} 128$ $\mu \mathrm{g} / \mathrm{mL}$, range $2-256 \mu \mathrm{g} / \mathrm{mL}$ ); most strains remained highly resistant. All of the MRSA strains were susceptible to vancomycin $\left(\mathrm{MIC}_{50}, 1 \mu \mathrm{g} / \mathrm{mL}\right.$ : $\mathrm{MIC}_{90} 2 \mu \mathrm{g} / \mathrm{mL}$; range $0.25-2$ $\mu \mathrm{g} / \mathrm{mL})$.

In vivo study. (I) Susceptibility of challenged strains. The MICs and minimal bactericidal concentrations $(\mu \mathrm{g} / \mathrm{mL})$ of the three different antibiotics for the four strains used in vivo were as follows: MSSA-1 - oxacillin 0.25/64, Augmentin 1.0/16, vancomycin 1.0/4.0; MSSA2-oxacillin 2.0/64, Augmentin 1.0/32, vancomycin 1.0/4.0; MRSA-1 - oxacillin 64/512, Augmentin 16/64, vancomycin 1.0/8.0; MRSA-2-oxacillin 64/512, Augmentin $16 / 64$, vancomycin $0.25 / 8.0$.

(2) Antibiotic serum levels. After a dose of $150 \mathrm{mg} / \mathrm{kg}$ of amoxicillin-clavulanate sc the peak serum level of amoxicillin reached $93 \pm 31 \mu \mathrm{g} / \mathrm{mL}$, dropping to no detectable levels after $4 \mathrm{~h}$. The peak serum level of clavulanic acid was $21 \pm 7 \mu \mathrm{g} / \mathrm{mL}$ and after $2 \mathrm{~h}$ no clavulanic acid was detectable. After one injection of cloxacillin $200 \mathrm{mg} / \mathrm{kg}$ sc, the peak serum level exceeded $200 \mu \mathrm{g} / \mathrm{mL}$, but no antibiotic was found in serum $4 \mathrm{~h}$ later. One injection of vancomycin $30 \mathrm{mg} / \mathrm{kg} \mathrm{sc}$ resulted in a peak of $36 \mu \mathrm{g} / \mathrm{mL}$, however, levels were undetectable $6 \mathrm{~h}$ later. Thus, at the dosage used in rats, the antibiotics used in these experiments reached peak levels comparable to those in humans after conventional therapeutic doses.

Comparative efficacy of treatment for $3 d$. (1) MSSA strains. Cloxacillin given at $200 \mathrm{mg} / \mathrm{kg}$ every $5 \mathrm{~h}$, and amoxicillin/clavulanate given at $150 \mathrm{mg} / \mathrm{kg}$ every $5 \mathrm{~h}$ were both highly and equally effective $\left(P<10^{-10}\right.$ compared to controls), sterilizing more than $90 \%$ of the infected vegetations (figure 2, upper part). The vancomycin $30 \mathrm{mg} / \mathrm{kg}$ regimen given twice a day (figure 2 ) was effective in reducing valvular infection $\left(P<10^{-2}\right.$ compared to controls), but remained less active than cloxacillin and amoxicillinclavulanate. When the vancomycin dosage was increased to $30 \mathrm{mg} / \mathrm{kg}$ every $6 \mathrm{~h}$ (figure 2, upper right), the efficacy of the three different antibiotics became similar.

(2) MRSA strains. As expected, the cloxacillin regimen clearly failed to cure infection and all of the rats remained highly infected after $3 \mathrm{~d}$ of treatment (figure 2, lower panels). In contrast, amoxicillin-clavulanate showed a definite efficacy against both MRSA strains $\left(P<10^{-5}\right.$ with MRSA-1 and $P<10^{-3}$ with MRSA-2, when compared to controls) and sterilized $>90 \%$ of the infected vegetations.

With regard to vancomycin, the twice-a-day regimen 

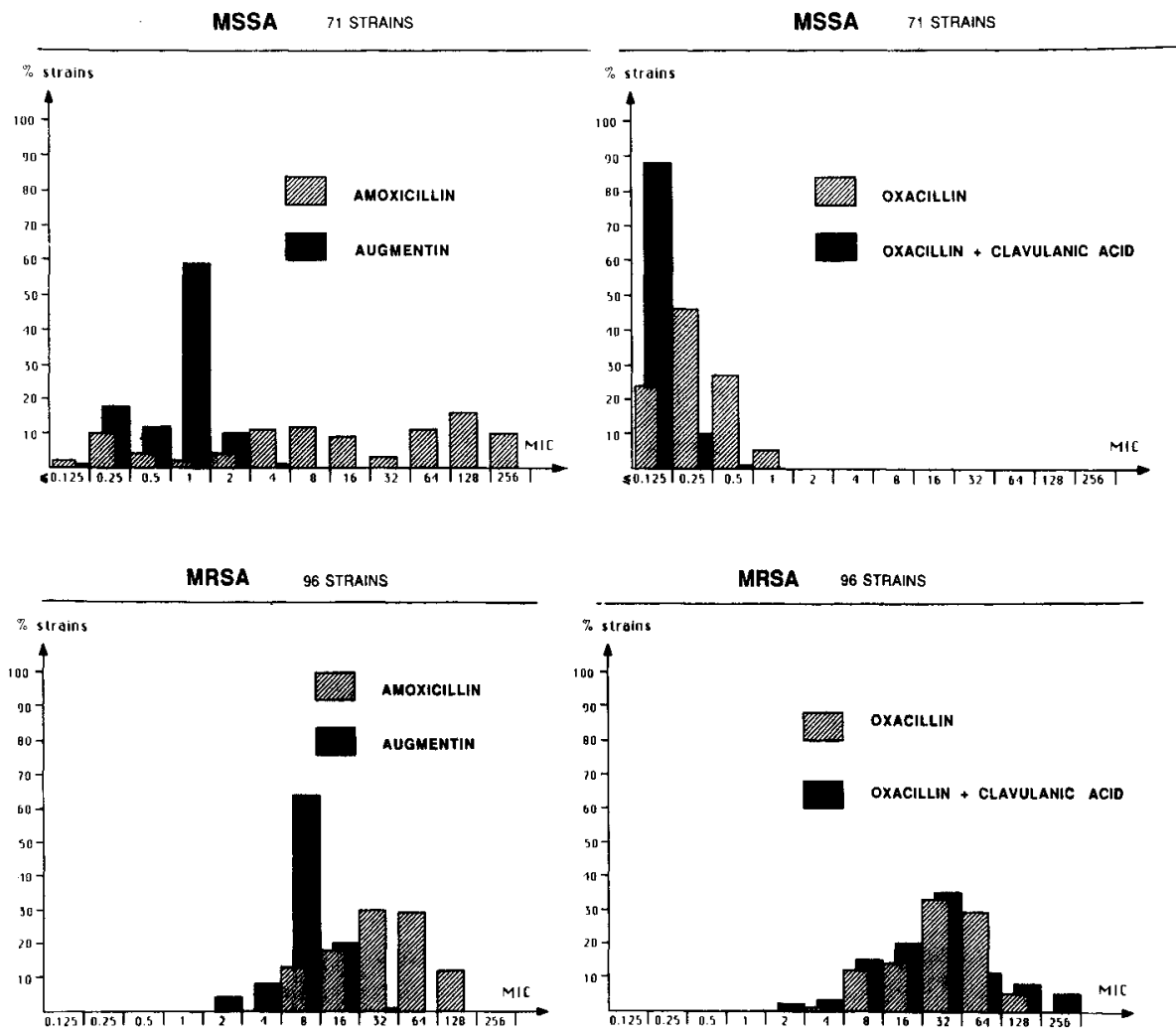

Figure 1. In vitro MIC determination (microbroth dilution) expressed as a percentage of strains inhibited at different antibiotic concentrations. Upper, Methicillin-susceptible strains (MSSA). Lower, Methicillin-resistant strains (MRSA). Amoxicillin-clavulanate was given in a ratio of $2: 1$.

used against the MRSA-1 strain failed to produce a significant effect on the valvular counts when compared to controls $(P=.6)$; increasing the doses to four times a day only marginally improved the outcome of infection ( $P=.1$ when compared to controls). Against the MRSA-2 strain, vancomycin given four times a day improved outcome when compared to controls $(P=.01)$ and to cloxacillin $(P=.01)$, but was clearly less effective than amoxicillin-clavulanate ( $P=.02$ ) (figure 2, lower right).

MICs of bacteria recovered from rats that remained infected at the end of the various treatments were equal to those of the organisms used for the bacterial challenge.

\section{Discussion}

This study of the treatment of methicillin-resistant $S$. aureus endocarditis in rats revealed three interesting observations. (I) Clavulanic acid markedly reduced the amoxicillin-resistance of the MRSA strains in vitro, but had little effect on the oxacillin-resistance of those organisms. (2) The combination of amoxicillin-clavulanate (Augmentin) was very effective in vivo not only against MSSA but also, and more importantly, against MRSA strains that were marginally susceptible to this combination in vitro according to current MIC interpretive standards [7]. (3) Vancomycin was less active in vivo than amoxicillinclavulanate against MRSA strains, whereas it was uniformly active against these organisms in vitro.

With regard to the in vitro results, most of the MRSA strains are also $\beta$-lactamase producers so that penicillin derivatives other than penicillinase-resistant penicillins are rarely if ever tested against them. When clavulanic acid is associated with $\beta$-lactam antibiotics to neutralize the effect of $\beta$-lactamases, an enhanced in vitro effect of the penicillinase sensitive penicillins when compared to that of the penicillinase resistant penicillins alone can be observed on MRSA strains. This phenomenon has already been observed both with amoxicillin-clavulanate combination [2-4] and with an ampicillin-sulbactam combination $[10,11]$, and might relate to the observation that penicillin and amoxicillin display a greater in vitro activity on penicillin-sensitive $S$. aureus strains than do such penicillinase-resistant penicillins as oxacillin or methicillin. This difference in intrinsic activity may be ascribed to differences in the target molecules to which the respective $\beta$-lactam antibiotics attach, e.g., differences in target 

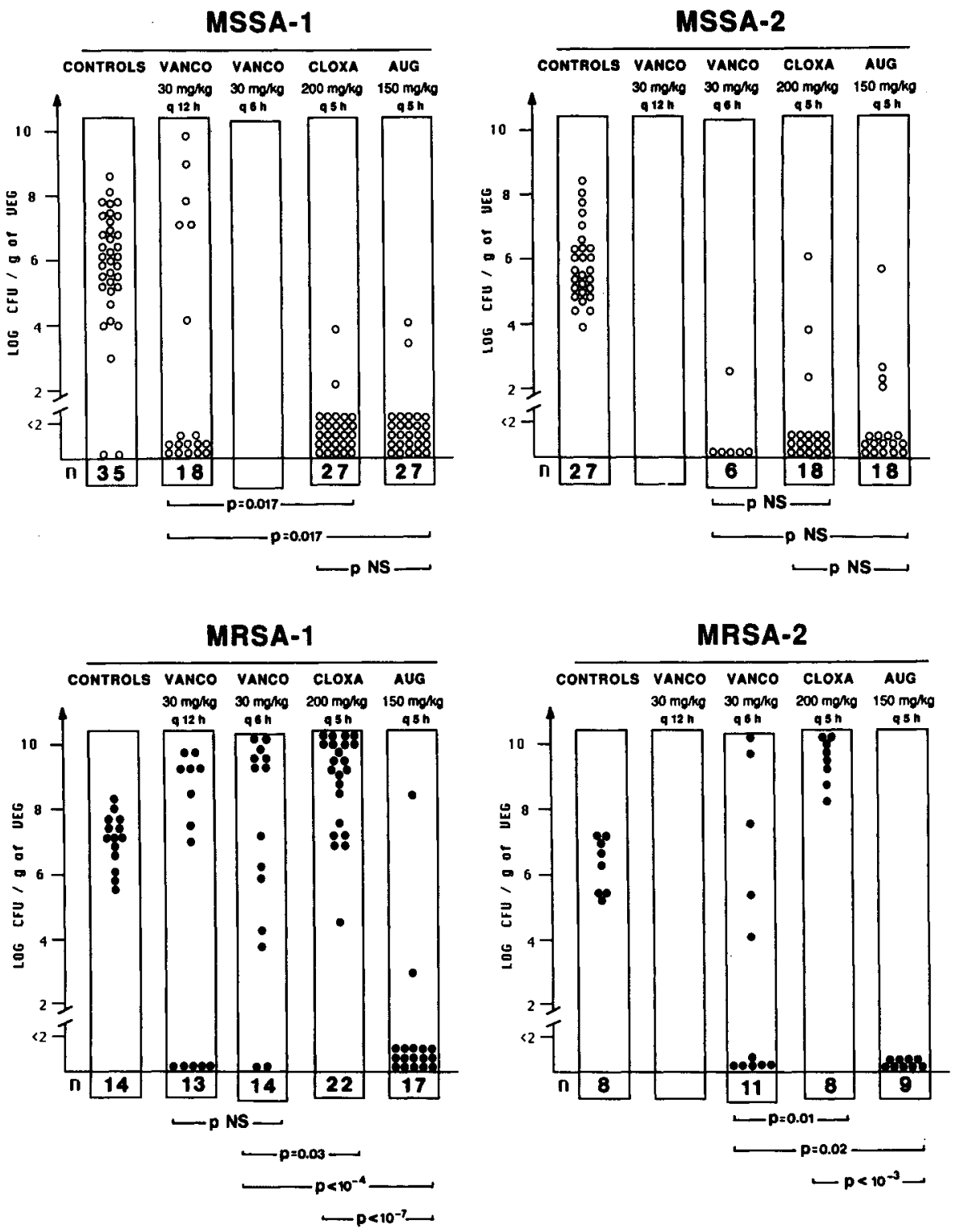

Figure 2. Treatment for $3 \mathrm{~d}$ with various antibiotic regimens begun $12 \mathrm{~h}$ after bacterial challenge. Each point represents the number of organisms recovered in aortic valve vegetations (veg) $12 \mathrm{~h}$ after completion of therapy. For controls, values are those found in rats killed at beginning of treatment. Numbers at the bottom of each column are the number of rats in each category of treatment: vanco = vancomycin, cloxa = cloxacillin, aug = Augmentin (amoxicillin plus clavulanate). MSSA = methicillin-susceptible strains, MRSA = methicillin-resistant strains.

penicillin binding proteins [4]. Such differences may explain why the addition of clavulanic acid to oxacillin had no beneficial effect on the MICs of MRSA strains while it improved the MIC of amoxicillin.

With regard to the marked in vivo efficacy of amoxicillin-clavulanate against MRSA strains, Washburn and Durack [5] obtained similar results with a combination of ampicillin and sulbactam in a rabbit model of endocarditis infected with a nafcillin-resistant $S$. aureus. As in our study, according to the MIC interpretive standards, the strains studied by Washburn and Durack were only marginally sensitive in vitro to the combination of ampicillin and $\beta$-lactamase inhibitor. The MIC for sulbactamampicillin was $25 \mu \mathrm{g} / \mathrm{mL}$ in the Washburn-Durack experiments, while the amoxicillin-clavulanate MIC was 16 $\mu \mathrm{g} / \mathrm{mL}$ for both MRSA strains in our experiments. Thus, both studies suggest that despite moderate in vitro sensitivities, the combination of ampicillin (respective of amoxicillin) with a $\beta$-lactamase inhibitor might exhibit excellent effectiveness in vivo. The doses used in both animal 
models of endocarditis (rabbit and rat) were chosen so as to give serum levels similar to those achieved in humans receiving full parenteral therapy.

With respect to the in vitro interpretive standard for sensitivity or resistance of staphylococci to amoxicillinclavulanate (resistant category, MIC $\geqslant 8 \mu \mathrm{g} / \mathrm{mL}$ ), most of the MRSA strains were resistant in our study, having an MIC of 8 or $16 \mu \mathrm{g} / \mathrm{mL}$. If one considers, however, the similar break-point value proposed for organisms other than staphylococci, most of the strains would be considered to be susceptible (MIC $\leqslant 8 \mu \mathrm{g} / \mathrm{mL}$ ) or moderately susceptible (MIC $=16 \mu \mathrm{g} / \mathrm{mL}$ ) to the combination. Likewise, the usual MIC values of the MSSA strains for amoxicillin-clavulanate are near the upper limit of susceptibility $(\leqslant 4 \mu \mathrm{g} / \mathrm{mL})$, if one considers the category MIC break points for staphylococci only. Given the success of treatment with a combination of ampicillin (amoxicillin) plus clavulanic acid achieved in experimental endocarditis due to several MRSA strains, perhaps it would be worthwhile to reconsider the interpretive break points for MICs currently recommended for Augmentin against staphylococci [6].

With regard to the efficacy of vancomycin against the MRSA strains, while it showed an excellent in vitro activity, its in vivo efficacy was inferior to that of amoxicillinclavulanate after $3 \mathrm{~d}$ of treatment. While unpublished experiments have shown that this difference disappeared after $6 \mathrm{~d}$ of treatment, amoxicillin-clavulanate sterilized the vegetations faster than did vancomycin.

Thus, the association of amoxicillin and clavulanic acid (Augmentin) was shown to be effective in the treatment of experimental endocarditis due to both MSSA and MRSA strains. They proved particularly superior to the efficacy of vancomycin against the MRSA strains. If this observation is confirmed in other infections due to MRSA strains, amoxicillin-clavulanate could be considered for clinical trials in the treatment of infections caused by MRSA strains.

L. Cantoni, A. Wenger, M. P. Glauser, J. Bille

Department of Internal Medicine, Division of Infectious Diseases, Centre Hospitalier Universitaire Vaudois, Lausanne, Switzerland

\section{References}

1. Chambers HF. Methicillin-resistant staphylococci. Clin Microbiol Rev 1988;1:173-186

2. Graninger N, Leitha T, Georgopoulos A, Witte W, Griffin K. Antimicrobial activity of penicillins plus clavulanic acid against Staphylococcus aureus [abstract]. In: Proceedings of the 7th International Symposium on Future Trends in Chemotherapy, 1986

3. Hofstra SY, Van de Sande F, Mouton RP. The effect of clavulanic acid on the activity of penicillins on methicillin resistant S. epidermidis and S. aureus. Proceedings of the 13th ICC, Vienna, 1983:55/12-55/15

4. McDougal LK, Thornsberry $C$. The role of $\beta$-lactamase in staphylococcal resistance to penicillinase-resistant penicillins and cephalosporins. J Clin Microbiol 1986;23:832-839

5. Washburn RG, Durack DT. Efficacy of ampicillin plus a $\beta$ lactamase inhibitor (CP-45,899) in experimental endocarditis due to Staphylococcus aureus. J Infect Dis 1981;144: 237-243

6. National Committee for Clinical Laboratory Standards. (Approved standard M2-A3 and supplement M100-S, M2-A3S1, table 2). Performance standards for antimicrobial disk susceptibility tests. Villanova, Pa: National Committee for Clinical Laboratory Standards, 1984

7. National Committee for Clinical Laboratory Standards. Tentative standard: M7-T and M110-S M7-A, S1, table 7. Standard methods for dilution antimicrobial susceptibility tests for bacteria which grow aerobically. Villanova, $\mathrm{Pa}$ : National Committee for Clinical Laboratory Standards, 1982

8. Schoenknecht FD, Sabath LD, Thornsberry C. Susceptibility tests: special tests. In: Lennette EH, Balows A, Hausler WJ Jr, Shadomy HJ, eds. Manual of clinical microbiology. Washington, DC: American Society for Microbiology, 1985

9. Heraief E, Glauser MP, Freedmann LR. Vancomycin prophylaxis of streptococcal endocarditis in rats. In: Nelson JD, Grassi C, eds. Current chemotherapy and infectious disease. Vol 2. Washington DC: American Society for Microbiology, 1980:911-913

10. Retsema JA, English AR, Girard AE, Anderson M, Brennan L, Cimochowski C, Faiella J, Herbert C. Sulbactam and ampicillin: synergistic antibacterial activity against hospital isolates of enterobacteriaceae, methicillin-resistant staphylococcus, and anaerobes. In: Proceedings of the 13th ICC, Vienna, 1983(59):59/1

11. Kazmierczak A, Duez JM, Pechinot A, Nordmann P, Labia R. In vitro bactericidal activity of sulbactam plus ampicillin against methicillin-resistant Staphylococcus aureus. Rev Infect Dis 1986;8(S5):S549-S554 